\title{
Roll 2208
}

GA 1485 (REV. 4/88)

ISSUE SUMMARY

\begin{tabular}{|c|c|c|c|c|c|}
\hline $\begin{array}{l}\text { TITLE } \\
\text { MHTGR Core }\end{array}$ & Tempera & ure Measu & ement Tra & 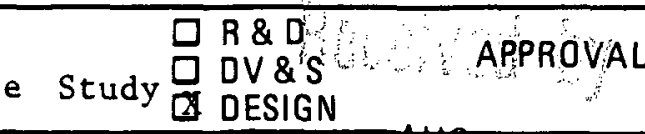 & LEVEL \\
\hline $\begin{array}{l}\text { DISCIPLINE } \\
\text { M }\end{array}$ & $\begin{array}{r}\text { SYSTEM } \\
11\end{array}$ & $\begin{array}{l}\text { DOC. TYPE } \\
\text { RGE }\end{array}$ & $\begin{array}{c}\text { PROJECT } \\
6300\end{array}$ & $\begin{array}{l}\text { DOCUMENT N0. } \\
\text { DOE-HTGR-88307 }\end{array}$ & $\begin{array}{c}\text { ISSUE NO./LTR. } \\
0\end{array}$ \\
\hline
\end{tabular}

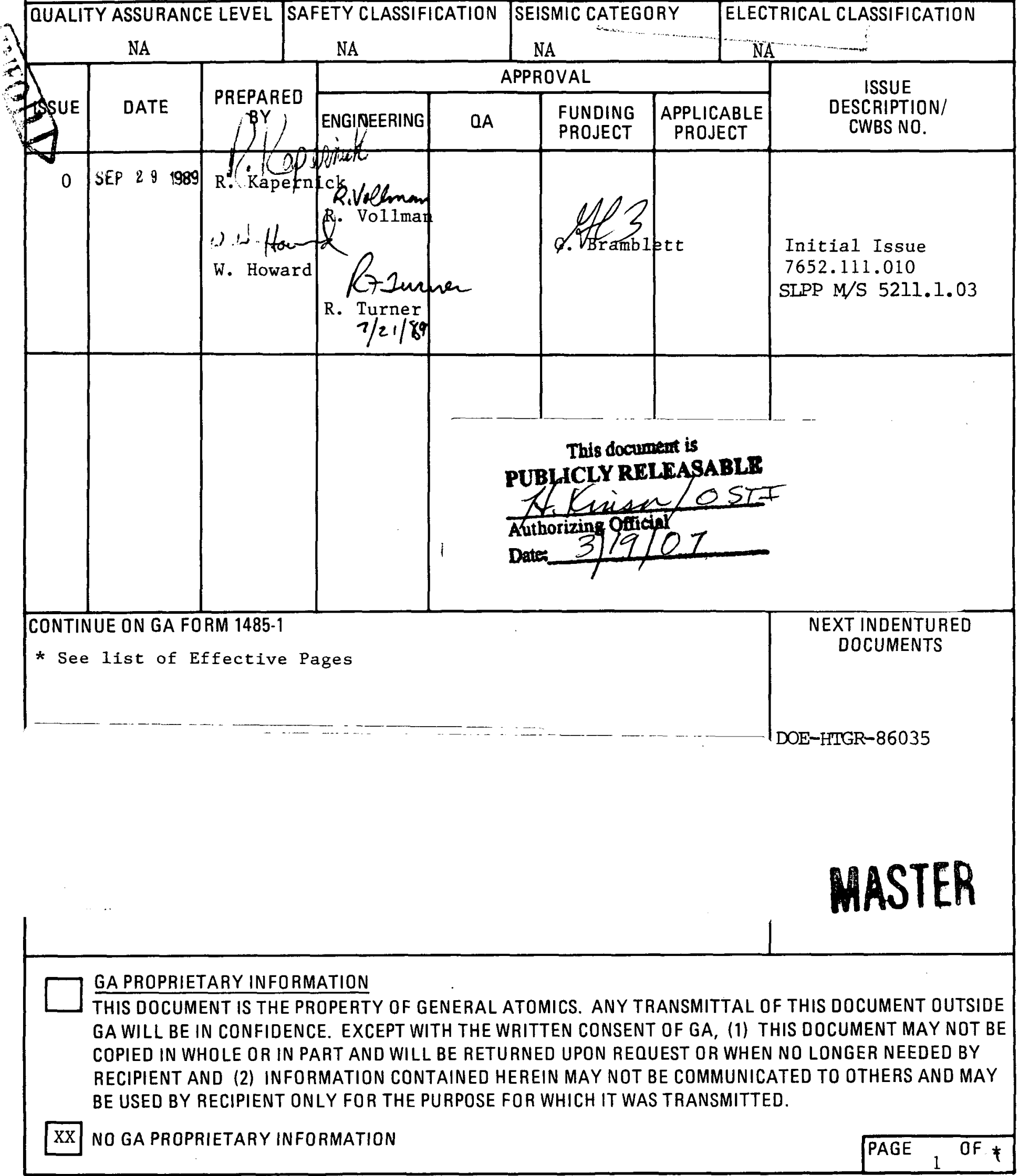




\section{DISCLAIMER}

This report was prepared as an account of work sponsored by an agency of the United States Government. Neither the United States Government nor any agency Thereof, nor any of their employees, makes any warranty, express or implied, or assumes any legal liability or responsibility for the accuracy, completeness, or usefulness of any information, apparatus, product, or process disclosed, or represents that its use would not infringe privately owned rights. Reference herein to any specific commercial product, process, or service by trade name, trademark, manufacturer, or otherwise does not necessarily constitute or imply its endorsement, recommendation, or favoring by the United States Government or any agency thereof. The views and opinions of authors expressed herein do not necessarily state or reflect those of the United States Government or any agency thereof. 


\section{DISCLAIMER}

Portions of this document may be illegible in electronic image products. Images are produced from the best available original document. 


\section{LEGAL NOTICE}

\section{CAUTION}

Do not publicly release this document.

This technical report is being transmitted in advance of DOE patent clearance and no further dissemination or publication shall be made of the report without prior approval of the DOE Patent Counsel.

This document will be returned upon request ox when no longer needed, unless notification has been received that this document has been cleared for release or publication.
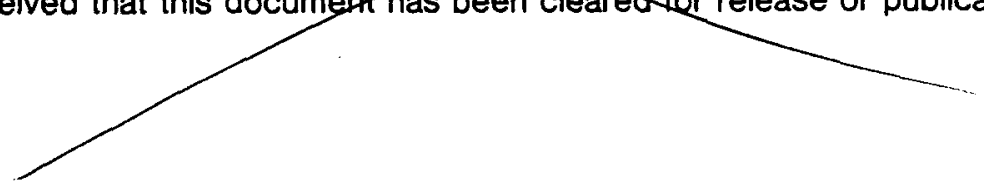

\section{DISCLAIMER}

This document was prepared under a contract sponsored by an agency of the United States Government. Neither the contractor nor any subcontractor of any tier nor any employee of any of them makes any warranty, express or implied, or assumes any legal liability or responsibility for the accuracy, completeness, or usefulness of any information, apparatus, product, or process disclosed, or represents that its use would not infringe any privately owned rights. References herein to any specific commercial product, process or service by trade name, trademark, manufacturer, or otherwise, does not necessarily constitute or imply its endorsement, recommendation, or favoring by any Contractor or Subcontractor of any tier. 


\section{LIST OF EFFECTIVE PAGES}

Page Number

Issue Summary

2 through 35

Total Pages
Page Count

1

$\underline{35}$

36
Revision

0

0 
CONTENTS

1. SUMMARY . . . . . . . . . . . . . . . . . . . 5

2. INTRODUCTION . . . . . . . . . . . . . . . . 6

3. INVESTMENT RISK ASSESSMENT . . . . . . . . . . . . . . . 8

3.1. General Discussion . . . . . . . . . . . 8

3.2 Primary Loop Flow Leakages and Core Bypass Flow . . . . . 8

3.2.1. Effect on Fuel and Coolant Temperatures . . . . 10

3.2.2. Consequences of Temperature Increases . . . . . 10

3.2.3. Detection of Core Bypass Flow or Flow Leakages . . . . . . . . . . . . . 15

3.2.4. Probability of Occurrence of Unexpected Flow Leakages and/or Core Bypass Flow . . . . . 15

3.3. Coolant Channel Flow Blockages . . . . . . . . . . 15

3.3.1. Effect on Fuel and Coolant Temperatures . . . . 15

3.3.2. Consequences of Temperature Increases . . . . . . 18

3.3.3. Detection of Flow Blockage Events . . . . . . 20

3.3.4. Probability of Occurrence of Flow Blockage

Events . . . . . . . . . . . . . . . 22

3.4 Off-design Core Power Distributions . . . . . . . . 25

3.4.1. Effect of Mislocated Fuel Element on Fuel and Coolant Temperatures ........... 26

3.4.2. Consequences of Temperature Increases . . . . . 27

3.4.3. Detection of Fuel Block Mislocation Events . . . 34

3.4.4. Probability of Occurrence of a Mislocated Fuel Element . . . . . . . . . . . . 34

4. REFERENCES . . . . . . . . . . . . . . . . . . 35

FIGURES

3.1. Fuel temps vs. leakage flow fraction ............ 11

3.2. Fuel temps vs leakage flow fraction . . . . . . . . . . . . 12

3.3. Coolant exit temps vs leakage flow fraction . . . . . . . 13

3.4. Mislocated fuel block fuel temperatures . . . . . . . . 28

3.5. Mislocated fuel block column average coolant temperature . . 29 
FIGURES (Continued)

3.6. Mislocated fuel block $1 / 7$ column average coolant temperature . . . . . . . . . . . . . . . . 30

3.7. Mislocated fuel block $1 / 7$ column fuel temperature...... 31 
1. SUMMARY

The objective of this task was to assess the need for core nonnuclear instrumentation. Since instrumentation has already been selected to operate the plant (Goal 1 ) and to ensure public safety (Goal 3 ), the focus of this study was the evaluation of core investment risk events (Goal 2). Three categories of events were considered: 1) unanticipated primary loop flow leakages and core bypass flows, 2) core coolant channel flow blockages and 3 ) off-design core power distributions. The measurements that were considered include column average coolant exit temperatures, core average coolant exit temperature, core pressure drop and core flow rate. The findings are summarized below:

1. Increases in loop flow leakages and core bypass flows due to seal fallures and clearance tolerances are calculated to be only a few percent at most. The temperature increases associated with the small increases in bypass or leakage flows are also small, and can be accommodated (with some penalty) along with the other uncertainties in the MHTGR design.

2. Coolant channel flow blockages could produce very high fuel temperatures which could result in fuel fallure, but are judged to be very low probability events. Similarly, a misloaded or mislocated fuel element could produce very high temperatures but is judged to be a very low probability event.

3. The risk that the calculated core power distribution will be seriously in error is low given that Peach Bottom and Fort St. Vrain power distributions were calculated within about $10 \%$, that the MHTGR is a small and tightly coupled core, that zero power flux measurements are envisioned as part of the rise to power testing program and that periodic axial flux measurements will be made during operation. 
4. The only measurements capable of detecting core flow or power distribution anomalies are individual column exit temperature measurements. Even with these measurements, the probability of detecting localized flow blockages or mislocated fuel blocks is very low. Major flow blockages could possibly be detected, but are judged to be extremely low probability events.

Based on these findings it is concluded that there is no compelling justification for additional nth-of-a-kind core instrumentation. However, this conclusion is made in the absence of a comprehensive investment risk analysis, and must be considered tentative pending completion of this analysis. The investment risk assessment includes quantification of event frequencles, consequences (downtime and other costs), mitigation of consequences and/or downtime by added measurements (potential benefit of the measurement as a diagnostic tool to understand and locate an anomaly), and measurement costs. This information would form the basis for establishing whether or not additional measurements are cost-effective.

It should be noted also that, due to time constraints, some events which could cause off-design power distributions have not been evaluated. These include possible inadvertent insertion of reserve shutdown material or mislocation of a control rod. These events need to be assessed before a final recommendation can be made.

\section{INTRODUCTION}

In the conceptual design phase of the MHTGR, significant reductions were made in the radial core power peaking factors, compared to Fort St. Vrain and later large HTGR core designs. These improvements eliminated the need for the region flow control valves which had been employed in the earlier designs to control coolant temperature rises through the reactor core. 
The elimination of the flow control valves removed the sole existing requirement for the region exit thermocouples, which was to provide the information to position these valves. As a consequence, the core exit thermocouples were not included in the MHTGR design.

The elimination of the core exit thermocouples has raised a concern that there may not be adequate instrumentation to monitor core performance. Although core exit thermocouples (or other measurements) have never been required for reactor safety nor have they been part of the plant protective system, earlier Fort St. Vrain FSAR and later LHTGR GASSAR documents identified their use in detecting off-design events such as core flow blockages.

To date, measurements have been selected for reactor operation and to ensure public safety, both during normal operation and in the event of various accidents (such as inadvertent control rod withdrawal and lossof-core-cooling). These measurements include core power/flow ratio, steam generator helium inlet temperature and primary coolant circulating activity levels, all of which are part of the plant protective safety system.

In some instances, these measurements would not be adequate to detect less catastrophic events where the core may be overheated, and as a consequence damage to the core or downstream components incurred. These events do not concern public safety, since they do not cause rapid core-wide heatup or fuel degradation, but they do involve investment risk. These events are discussed in the following section. 


\section{INVESTMENT RISK ASSESSMENT}

\subsection{GENERAL DISCUSSION}

This study considers events that lead to moderate and/or localized temperature increases in the core and/or downstream components. For discussion, these events have been grouped into three categories: 1) primary loop flow leakages and core bypass flows, 2) coolant channel flow blockages in the core and 3 ) off-design core power distributions.

\subsection{PRIMARY LOOP FLOW LEAKAGES AND CORE BYPASS FLOW}

These two phenomena are discussed together because they both represent flow that is generated by the circulators but does not pass through the coolant channels.

Core bypass flow (more precisely coolant channel bypass flow) includes the core cavity flow in the gaps between the graphite blocks and the control rod channel flow. This flow varies axially, typically being a maximum at core mid-height and a minimum at the bottom. Locally, it depends on the gap widths between adjacent blocks, which can vary from zero to a relatively large value (about $1 / 2$ inch).

Leakage flows are those flows that are generated by the circulator, but do not make it to the core cavity. These flows may be grouped into three types: 1) flows from cold paths to cold paths, 2) flows from hot paths to cold paths and 3) flows from cold paths to hot paths.

This distinction is made because these types of leakage flows have different effects on system and core performance. Flows from the high to low pressure cold paths occur between the circulator discharge and intake. In the process, they bypass both the core and the steam generator and thus affect the steam generator helium inlet temperature. Since this temperature is measured, an increase in this type of leakage 
flow would be detected as a primary coolant temperature increase at the steam generator entrance, and measures would be taken to maintain the desired steam generator helium inlet temperature (i.e., drive the circulator harder), or to shut down to prevent damage.

Leakage flows from the hot paths to the cold paths can occur between the steam generator intake and the return flow to the circulator. These flows are small (less than $0.1 \%$ of the total flow). Their effect is to increase the circulator and core flows, to maintain the steam generator flow and heat load. Core exit coolant temperature remains the same, but core inlet temperature increases slightly. As a result, peak core temperatures are decreased slightly and average core temperatures are increased slightly.

Leakage flows from the cold to hot flow paths can occur at the cross duct foints, across the core barrel seal or through the shutdown cooling system (SCS). These leakage flows would bypass the core but not the steam generator. Consequently they, along with core bypass flows, can increase core temperatures without being detected by the steam generator helium inlet temperature measurements. These flows may present a concern with regard to investment risk, and are discussed in the following sections.

One additional leakage flow event from the cold to hot flow paths is the possible sticking of the SCS shutoff valve and subsequent operation on the HTS. A preliminary calculation shows this leakage flow could be as large as $31 \%$ of the total primary coolant loop flow. Note that measurements are envisioned that would detect whether or not this valve is open. An alarm would alert the operator if a condition existed where this valve were open while operating on the HTS. An interlock may also be included in the Plant Protective System to limit power when the SCS shutoff valve is open. 


\subsubsection{Effect on Fuel and Coolant Temperatures}

Calculations for the MHTGR (Ref. 1) have been performed that show the core bypass flow for a end-of-cycle uniform gap configuration varies from $16 \%$ at core inlet, to $24 \%$ at active core mid-height, to $11 \%$ at core exit. A single analysis for an expected (non-uniform) gap configuration shows the bypass flow can be slightly larger; $20 \%-25 \%-11 \%$ at core topmiddle-bottom.

Leakage flows from the hot to cold paths have been calculated to be about 1\% (Ref. 2). This is a nominal calculation. A bounding calculation has been performed, where it is assumed all seals have failed. Taking these results, and further assuming the core barrel bypass flow is 3 times nominal, produces a leakage flow of about $3 \%$.

Based on the leakage and bypass flows given above, uncertainty in the flow bypassing the coolant channels is on the order of a few percent. Representative calculations for the effect of greater flow bypass/leakage have been performed using additional flow losses of $2 \%$ and $5 \%$. These results are presented in Figs. 3.1-3.3.

Figure 3.1 shows the increase in fuel temperatures versus. leakage flow fraction; Fig. 3.2 is a blowup of the high-temperature end of Fig. 3.1. As can be seen, peak fuel temperatures are increased by about $25^{\circ} \mathrm{F}$ for $2 \%$ greater bypass or leakage flow, and by about $70^{\circ} \mathrm{F}$ for a $5 \%$ greater flow. The effect on core exit hotstreaks is similar to that for core fuel temperatures, and is shown in Fig. 3.3.

\subsubsection{Consequences of Temperature Increases}

\subsubsection{Fuel Performance}

The uncertainties in leakage/bypass flows are small. Their effect on fuel performance is also small and on the same order of magnitude as 
FIGURE 3.1

FUEL TEMPS VS. LEAKAGE FLOW FRACTION

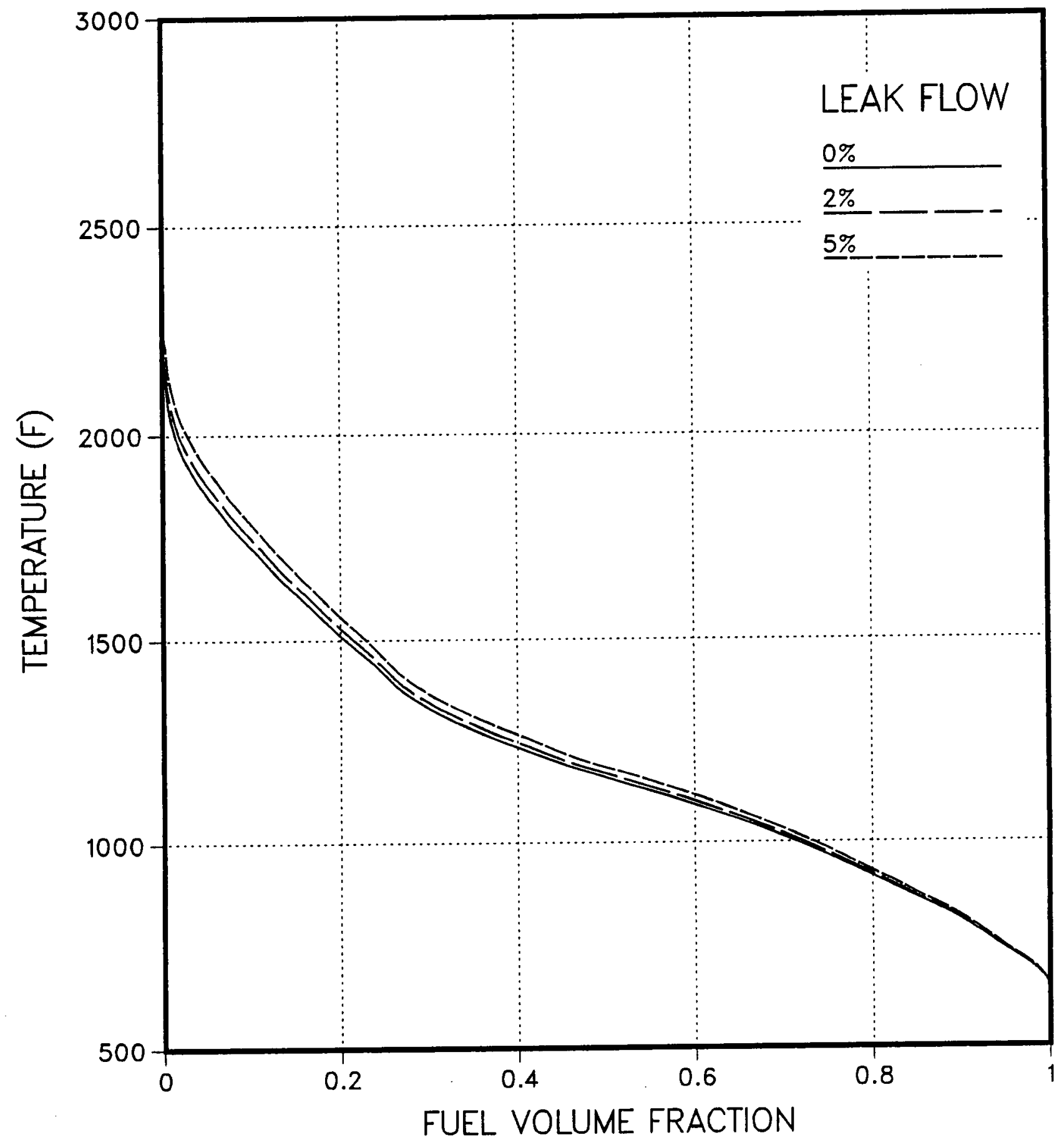


FIGURE 3.2

FUEL TEMPS VS. LEAKAGE FLOW FRACTION

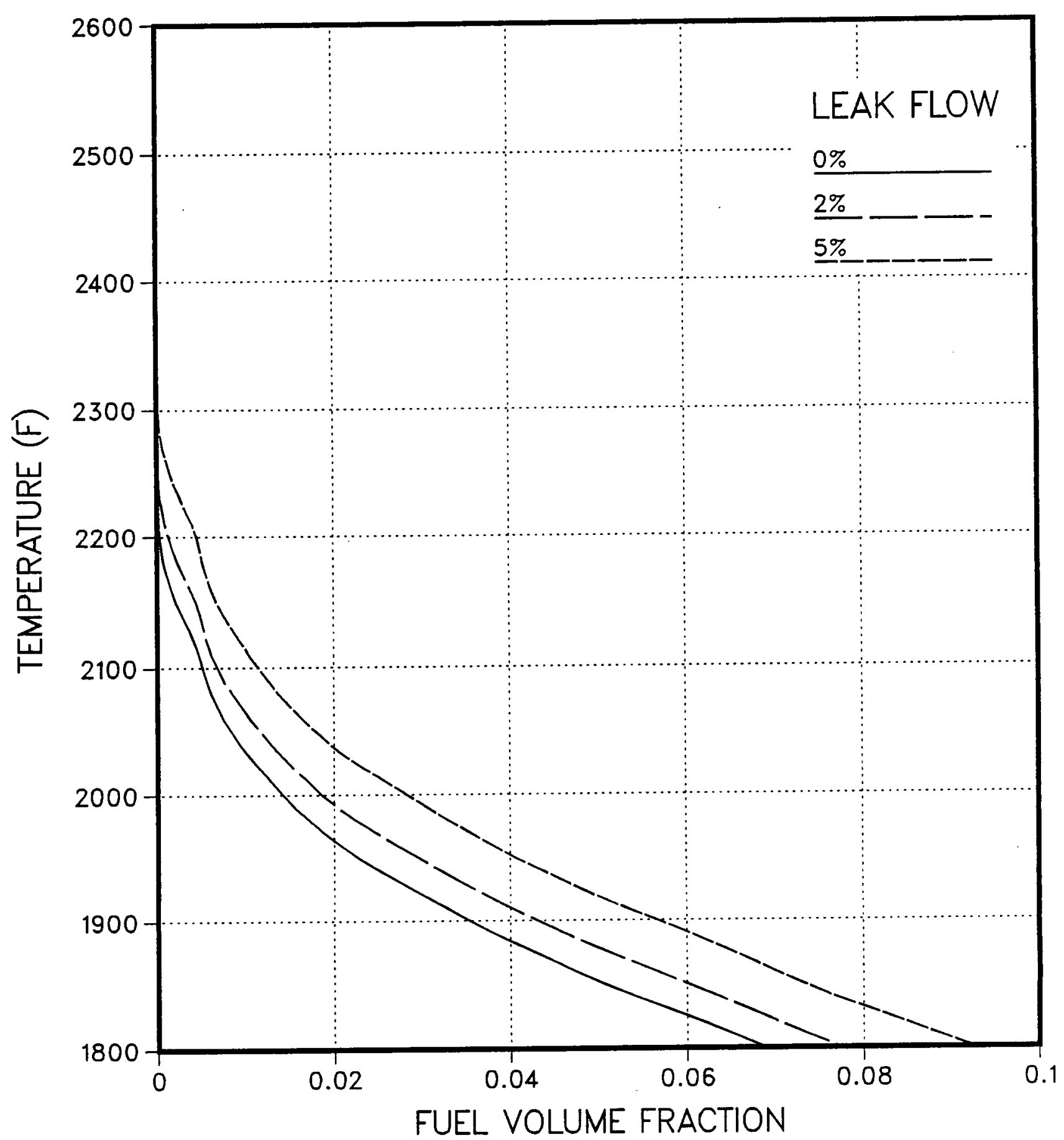




\section{FIGURE 3.3 \\ COOLANT EXIT TEMPS VS. LEAKAGE FLOW FRACTION}

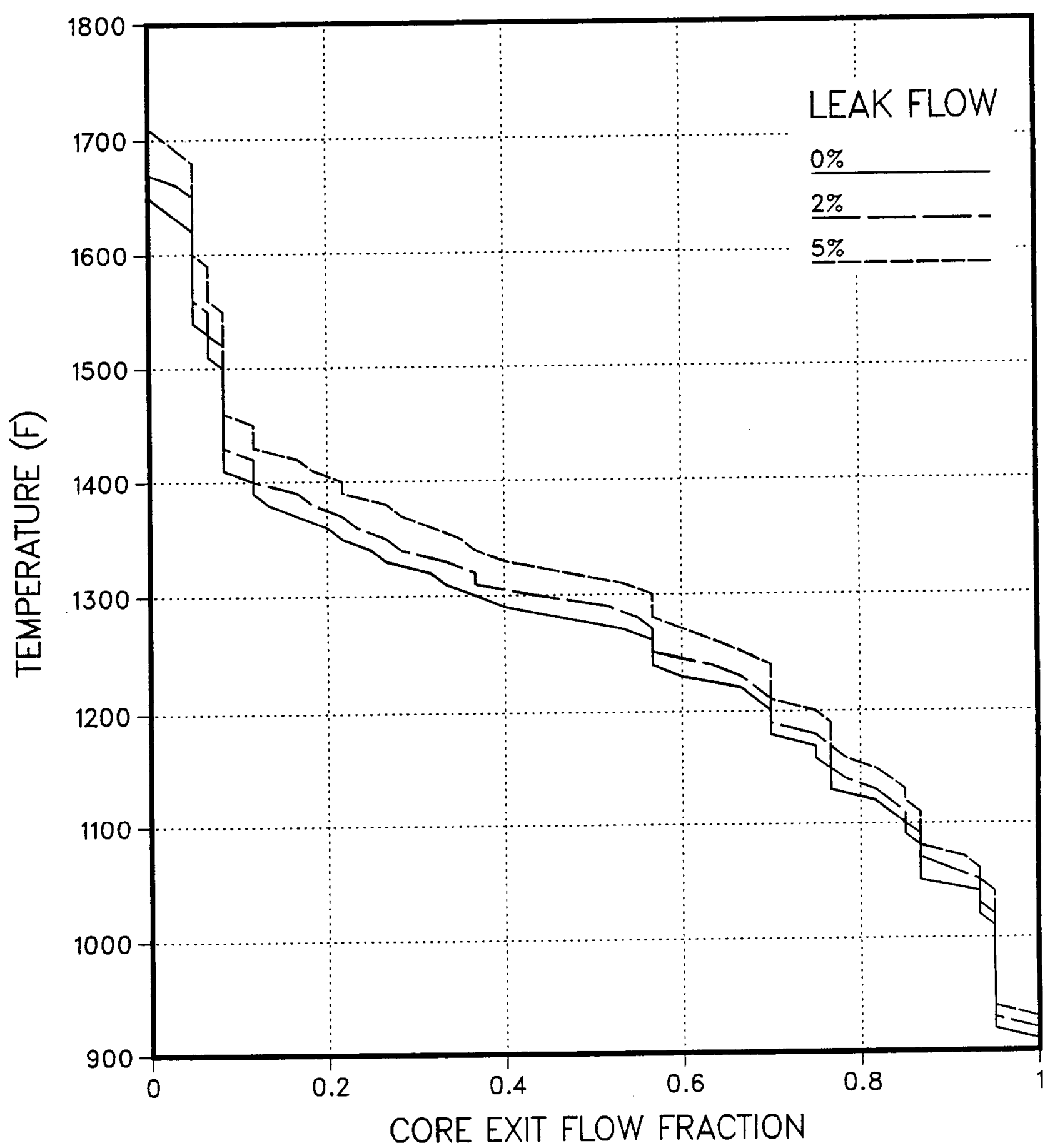


various other uncertainties (e.g., thermal conductivities, power distribution).

\subsubsection{Graphite Block Integrity}

To a first approximation, temperature differences in a block are about proportional to the coolant channel flow in the block and stresses are somewhat less than proportional to these temperature differences. Thus a $2 \%$ or $5 \%$ additional bypass or leakage flow would lead to an increase in block stress of somewhat less than $2 \%-5 \%$.

These small increases will increase slightly the risk of cracking of the blocks but would not lead to a catastrophic failure of the blocks that would require plant shutdown.

\subsubsection{Coolant Temperature Streaks}

The magnitudes of hotstreak temperature increases downstream from the core exit plane depend on both the source of bypass/leakage flow and on its characteristics. However, given that all of these additional bypass and leakage flows are small, and that they have small hydraulic diameters and thus mix readily with the main stream flow, the potential effect on hot duct or steam generator performance is small and believed acceptable.

\subsubsection{Control Rods}

The small increases in control rod temperatures associated with the possible additional leakage or core bypass flows are small and acceptable. 


\subsubsection{Detection of Core Bypass Flow or Flow Leakages}

The measurements that have been considered are: 1) flow in the 11 rectangular channels attached to the core barrel (risers), 2) core pressure drop, 3) core average exit temperature and 4) individual column coolant temperatures. All of these measurements have uncertainty associated with them roughly equal to or greater than the uncertainty in leakage or bypass flows, and thus would not be effective in detecting these small increases.

\subsubsection{Probability of Occurrence of Unexpected Flow Leakages and/or Core} Bypass Flow

As noted earlier, assuming that all the seals fail produces only a small increase in leakage flow, of a few percent. The probability of complete fallure of all seals is very low. There is a greater probability of failure of one seal, but the associated leakage is even smaller.

\subsection{COOLANT CHANNEL FLOW BLOCKAGES}

\subsubsection{Effect on Fuel and Coolant Temperatures}

Analysis for the effect of postulated coolant flow blockages has not been performed for the MHTGR. Consequently, much of the discussion presented in this section has been taken from GASSAR, which pertains to the $3000 \mathrm{MW}(t)$ HTGR design. The effect of differences in the two designs on the calculated temperature increases has been estimated.

Coolant channel flow obstructions may occur for several reasons:

1. Debris in the primary coolant loop, such as chips of graphite or small pieces of insulation. 
2. Damage to a fuel element, either before or during operation.

3. Any foreign objects left in the upper plenum during assembly or refueling.

4. Mislocating a fuel or reflector element.

These events have in common that the flow blockage would be localized and the blockage could be anywhere from partial to total.

Analyses were performed for GASSAR, where blockages of 1,4 and 10 adjacent coolant holes were assumed. It should be noted that the fuel element design for the $3000 \mathrm{MW}(t)$ reactor was different than for the MHTGR, having fewer, larger fuel and coolant holes. The equivalent number of blocked holes in the MHTGR is about 1.5, 6 and 15. The other significant difference was in power density; the power density in the MHTGR is about $25 \%$ lower.

Values for the MHTGR have been derived from the GASSAR results, and are given in the table below. The table values are valid for full power operation and for the maximum peaking factor of 1.6 .

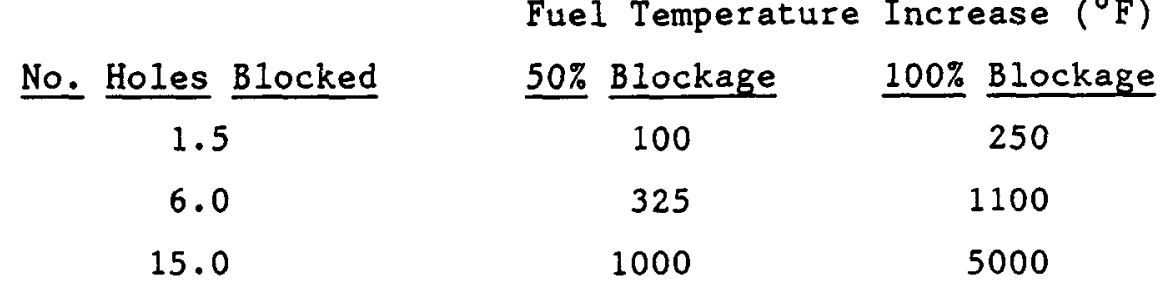

Flow blockages also lead to increases in core exit coolant temperatures, which impinge on the hot duct and steam generator downstream from the core. Two types of hot streak increases are possible: 1) when coolant channels are blocked the heat generated in the adjacent fuel channels must be removed by nearby coolant flows, increasing their 
temperatures, and 2) if the blocked coolant channels suddenly become unblocked, large coolant temperature spikes of short duration will occur in these channels.

The effect of flow blockage on hot streaks has been estimated assuming the blockage is localized to one corner of a fuel block. The power in this $1 / 6$ of a block is assumed to remain the same after the blockage (no reduction by temperature feedback), but the flow is reduced by the assumed number of blocked coolant channels. When this flow enters the bottom reflector transition block plenum it flows to the closest radial channel. In addition, some flow from the other $5 / 6$ of the block will add to this flow, such that the average flow in each of the six radial channels is equal.

Increases in core exit coolant temperature streaks due to localized coolant channel blockage are given in the table below. These estimates are based on the maximum peaking factor of 1.6 in the $1 / 6$ column, and the maximum column average peaking factor of 1.3 in the rest of the column. Also, it is assumed the blockage occurs at a core/side reflector location where the flow does not merge with flow from another column.

$$
\text { Coolant Temperature Increase }\left({ }^{\circ} \mathrm{F}\right)
$$

\begin{tabular}{|c|c|c|}
\hline No. Holes Blocked & 50\% Blockage & $100 \%$ Blockage \\
\hline 1.5 & 45 & 115 \\
\hline 6.0 & 250 & 530 \\
\hline 15.0 & 670 & 1270 \\
\hline
\end{tabular}

More severe hotstreaks could occur if coolant channels were to be blocked, the affected graphite were to heat up to a steady-state condition, and then the channels were suddenly to become unblocked.

Upper bound estimates for the hotstreak temperatures have been made for this case, using similar assumptions to those above, and are given 
in the table below. An additional input is the flow in the previously blocked channels, which is assumed to have an instantaneous temperature equal to the fuel temperature during the blockage. The hotstreak then comprises this flow, the higher temperature flow in the rest of the coolant channels in the $1 / 6$ section, and some makeup flow from the other $5 / 6$ of the column so the flows to the six radial channels are equal.

\begin{tabular}{|c|c|c|}
\hline \multirow[b]{2}{*}{ No. Holes Blocked } & \multicolumn{2}{|c|}{ Hotstreak Temperature Increase ( } \\
\hline & 50\% Blockage & $100 \%$ Blockage \\
\hline 1.5 & 60 & 155 \\
\hline 6.0 & 345 & 900 \\
\hline 15.0 & 1100 & 4010 \\
\hline
\end{tabular}

These hotstreaks are substantially higher than those estimated to occur during the blockage.

\subsubsection{Consequences of Temperature Increases}

\subsubsection{Fuel Performance}

Flow blockage of several adjacent coolant channels could lead to fuel particle coating damage and fission product release to the primary coolant. The increase in primary coolant activity would be gradual, and could ultimately lead to shutdown of the reactor as the limit on primary coolant activity is approached. The resultant downtime has not been estimated, but would be long. The cause of the coolant activity Increase would have to be determined, the damaged fuel located and replaced.

\subsubsection{Graphite Block Integrity}

Localized temperature increases could result in increased block stresses and limited block cracking. Extensive cracking would not be expected, however, since residual stresses in the block would reduce as 
a result of the local cracking. Also, graphite retains its strength even up to the very high temperatures associated with severe coolant blockages, so that catastrophic fallure of a block would not occur. Additional downtime could be incurred if cracks beyond those allowed in the design criteria were to occur.

\subsubsection{Coolent Temperature Streaks}

The effect of a localized coolant blockage in the core is considerably mitigated by the time the streak reaches the downstream metallic components. The estimated hotstreak flows in the previous section represent only about $0.25 \%$ of the total core flow $[1 /(66 * 6)]$.

The effect of the flow blockage on the hot duct and steam generator temperature streaks has been estimated using the temperature estimates given above and the temperature attenuation correlations. These results are given in the tables below:

Hot Duct

Temperature Increase $\left({ }^{\circ} \mathrm{F}\right)$

No. Holes Blocked

1.5

6.0

15.0
50\% Blockage

$3 / 4$

$15 / 21$

$40 / 66$
$100 \%$ Blockage

$7 / 9$

$32 / 54$

$76 / 241$

Steam Generator

Temperature Increase $\left({ }^{\circ} \mathrm{F}\right)$

No. Holes Blocked

1.5

$50 \%$ Blockage

$1 / 1$

$100 \%$ Blockage

6.0

$3 / 4$

$1 / 2$

15.0

$8 / 13$

$6 / 11$

$15 / 47$ 
The values before the slash represent the hotstreaks that could occur during a blockage event; the values after the slash represent transient hotstreaks that could result from an unblocking event.

Although definitive studies have not been performed, it is believed that, with the exception of the most severe flow blockages (15 or more coolant channels completely blocked), these temperature increases could be sustained for substantial time. The risk of damage is increased but remains small. Note the transient temperatures following an unblocking event would be of very short duration (less than 1 hour), and are generally less of a concern than the possible longer term but lower temperature hotstreak increases associated with a flow blockage.

\subsubsection{Control Rods}

The MHTGR differs significantly from earlier designs in that the control rods are located in the side reflectors, not in the core. Consequently, their temperatures are much less sensitive to possible coolant holes blockages in the core.

If a control rod channel were to be completely blocked, the temperature of the control rod would be a function of the temperature in the fuel columns near the control rod. Since power is depressed by the presence of the control rod, the nearby fuel blocks would not be expected to be operating at temperatures greater than about $1500^{\circ} \mathrm{F}$. At this temperature, damage to the cladding is not likely.

\subsubsection{Detection of Flow Blockage Events}

A possible means of detecting flow blockage events is by temperature measurements in the bottom reflector transition blocks in each fuel 
column. The instruments would be located in the flow plenums in these blocks, or in the blocks beneath the flow plenums, and would be designed to measure the column average temperature of the exiting coolants.

Detection of a flow blockage event in the core would be by comparison of the calculated and measured column exit temperatures (normalizing out the effects of loop flow leakages core coolant channel bypass flows). To be effective, the difference between these values must be larger than that which could be attributed to other causes, such as uncertainty in the calculated core power distribution, temperature measurement uncertainty, and uncertainties associated with core flow distribution (lower plenum pressure drop, non-uniform gap flows and crossflows).

The uncertainty in the radial peaking factors is $13 \%$, from Ref. 3 . Uncertainty in the measured coolant temperature arises from non-perfect mixing of the gas streams and from thermocouple calibration error. An estimate for these is about $50^{\circ} \mathrm{F}$ each, or an RMS value of about $70^{\circ} \mathrm{F}$. The effect of flow distribution has been evaluated by comparing the column outlet temperatures for an expected core operating condition (from the Ref. 1 core thermalhydraulic analysis), with those from a POKE analysis, where the effects of gap flow, crossflow, etc. are neglected. This comparison, for one time only, shows the temperature differences are less than $50^{\circ} \mathrm{F}$.

The power peaking factor uncertainty is stated to be a $2 \sigma$ value, and the estimates on temperature uncertainties may be taken to be $2 \sigma$ also. Combining these by RMS, for the high power column (RPF $=1.3$, $\left.\Delta \mathrm{T}=1160^{\circ} \mathrm{F}\right)$ :

$$
\begin{aligned}
& \Delta \Delta \mathrm{T}=\left(70^{2}+50^{2}+[0.13 * 1160)^{2}\right) 1 / 2 \\
& \Delta \Delta \mathrm{T}=174^{\circ} \mathrm{F}
\end{aligned}
$$


The increases in the column average exit coolant temperatures due to flow blockages are given below:

\begin{tabular}{|c|c|c|}
\hline \multirow[b]{2}{*}{ No. Holes Blocked } & \multicolumn{2}{|c|}{ Column Temperature Increase $\left({ }^{\circ} \mathrm{F}\right)$} \\
\hline & 50\% Blockage & $100 \%$ Blockage \\
\hline 1.5 & $11 / 14$ & $22 / 29$ \\
\hline 6.0 & $45 / 61$ & $92 / 154$ \\
\hline 15.0 & $115 / 187$ & $215 / 672$ \\
\hline
\end{tabular}

Here also, the values before the slash are for a flow blockage condition, and those after the slash are the instantaneous values following unblockage.

Comparing these estimates with the value of $174^{\circ} \mathrm{F}$ indicates the column coolant temperature measurements would be effective in detecting only very severe flow blockages. Smaller differences may be attributed to the calculation and measurement uncertainties. However, in the presence of an increase in primary loop circulating activity, measured small increases could prove useful in locating and understanding the problem.

\subsubsection{Probability of Occurrence of Flow Blockage Events}

All of the flow blockage events are belleved to have a very low probability of occurrence. Further, the probability of occurrence decreases substantially as the assumed number of blocked coolant holes increases or as the degree of blockage increases. The bases for these statements are given below.

The core upper plenum is formed by the layer of metallic plenum elements and the upper plenum shroud. The upper plenum shroud is a welded, segmented shell, with nothing attached on the Inside which could break loose. Inside the shroud, around the side, are side shield blocks. These blocks are integral metallic cans with the shield material inside. They have supports to the core barrel and upper plenum 
shroud, so that it is highly unlikely that one could break loose and migrate to the active core. Similarly, the neutron control assemblies are self-contained, and have no appendages that could detach and block coolant holes.

Although unlikely, it is possible that debris could be entrained and transported to the core inlet plenum, or that there could be some sort of debris left from fuel handling. However, even if debris were to be present in the core upper plenum, the chance of significant blockage is sma11.

The metallic plenum element design has two sets of coolant holes, which are offset and connected by a small internal plenum. The upper set comprises 54 holes, with each hole being 0.87 inches in diameter. The lower set matches the coolant hole pattern in the fuel block, with 108 coolant holes. Six of these are 0.5 inches in diameter, and the other 102 are 0.625 inches in diameter.

Debris that blocked some of the upper set of coolant holes would have little effect on the column flow rate. An estimate was made for the effect of blocking 8 of the 54 coolant holes, which showed that the flow in the column coolant holes would be reduced by on 1 y $1 \%$.

For debris to completely block flow in a core coolant hole, it would have to pass through the upper set of holes in the metallic plenum element, and then lodge In a lower coolant hole (i.e., be smaller than 0.87 inches, but be larger than 0.5 or 0.625 inches). To have several coolant holes blocked would require several pieces of debris of this size to enter the same metallic plenum element and enter adjacent coolant holes. 
Even in the event of blockage of one or more coolant holes at the top of the core, it is likely the affected hole(s) would have significant flow, due to crossflow from nearby coolant channels at the fuel block interfaces.

It is possible, although even more unlikely, that a fuel block could be damaged and a coolant hole blocked, say at mid-height in the core. In this event, flow in the affected hole in the affected fuel block could be zero. It is still likely, however, that in the fuel blocks above and below this block, there would be some flow in this coolant hole, by crossflow.

One of the other possibilities for flow blockage is failure of the supports of one of the side shields, and subsequent migration of this block to the active core area in the core upper plenum. Because of the dowels on the metallic plenum elements, which extend 0.87 inches above the upper face of the plenum elements, the side shield block could not rest flat on the metallic plenum elements. Consequently, even for such a very unlikely event, the flow to coolant channels would only be partially blocked.

Experience at Fort St. Vrain has never revealed any flow blockages, due elther to debris or block damage. Two fuel blocks removed during the second refueling were shown to have hairline cracks; but these cracks were caused by high stress during operation, not by damage from fuel handling, and they did not affect the flow in the fuel block.

Finally, flow blockage is possible as a result of a mislocated fuel or reflector block. Considerable thought has gone into the design of fuel handling equipment and procedures to prevent a fuel or reflector block from being mislocated. All blocks are stamped with a type number and a serial number. These numbers are checked by camera at each stage the block is handled (character recognition) to be sure 1 it is in the proper location and sequence, per the preprogrammed accountability. In 
addition the fuel handling machine performs weight checks and coolant hole checks (two independent detectors checking for presence of coolant holes). Also, all fuel handling operations are videotaped, so that playback is possible, if ever felt necessary.

Experience at Fort St. Vrain with fuel handling has been very positive. No blocks have been handled out of sequence or ever discovered to have been mislocated.

\subsection{OFF-DESIGN CORE POWER DISTRIBUTIONS}

Uncertalnties in the calculated core power distribution have been estimated and are accounted for in the design of the MHTGR. These are given in Ref. 3 as $\$ 13 \%$ for the radial power factors and $+10 \%$ for the axial power factors. These values have a 20 confidence. In the radial direction, they apply to a $1 / 7$ column area; in the axial direction they are considered point values.

There is some risk that the uncertainty values could be larger. However, this possibility is unlikely because the MHTGR core is radially a small, tightly-coupled core with very little risk of instability. Axially, there is greater concern with instability with burnup, and periodic axial in-core flux mapping will be performed to confirm axial stability. Also, it is planned to confirm the calculated power distribution by flux measurements during rise-to-power testing. Similar measurements confirmed the calculated power distributions in the Peach Bottom and Fort St. Vrain reactors.

Beyond the concern of uncertainties in the calculated power distribution being greater than the design values, there exists some risk that a fuel element could be mislocated. This event is discussed below. 
Other events that have not been assessed due to lack of time are: mislocated control rods, RSS material being advertently dumped into the core, and fuel and/or lumped burnable poison being misloaded into a fuel element.

\subsubsection{Effect of Mislocated Fuel Element on Fuel and Coolant}

\section{Temperatures}

The fuel is zoned radially to reduce power peaking at the core/side reflector interfaces, and axially to offset the coolant temperature rise. Radially, the zoning factors (fissile) are, by ring, $0.75,1.15$ and 1.04 (with 18 columns in the inner ring and 24 columns each in the outer two rings). Axially, the zoning factors are $1.21,0.93$ and 0.58 (with 5 fuel elements in the top zone, 3 in the second zone and 2 in the bottom zone).

If a fuel block were to be mislocated, the power in the block, to a first approximation, would be proportional to the fisslle loading. The most adverse case would be a ring 2, top zone fuel block inadvertently put in a ring 1 , bottom zone location. The power in this block would be increased by a factor of $[(1.15 * 1.21) /(0.75 * 0.58)=3.20]$.

Two analyses were performed, where it was assumed that the fuel elements in axial layers 9 or 10 of ring 1 contained a ring 2 top zone fuel element. In these analyses, it was assumed the other 9 fuel elements in the column were normal. Also, the calculation was performed for the highest peaking factor column in ring 1 (power peaking factor of 1.58 , in a reserve shutdown control column). 
The results of these calculations are shown in Figs. 3.4-3.7 and are summarized in the table below:

\begin{tabular}{ccccc} 
& \multicolumn{3}{c}{ Temperature Increase $\left({ }^{\circ} \mathrm{F}\right)$} \\
& $1 / 7$ Fuel Column & Column Average \\
Mislocated Block & $\frac{\Delta T \text {-fuel }}{800}$ & $\frac{\Delta T \text {-coo1 }}{280}$ & $\frac{\Delta T \text {-fuel }}{590}$ & $\frac{\Delta T \text {-coo1 }}{190}$ \\
Axial Layer 9 & 800 & 280 & 590 & 120 \\
Axial Layer 10 & 550 & 180 & 410 &
\end{tabular}

The $1 / 7$ fuel column values are for the maximum power $1 / 7$ subvolume in the column.

The increase in core exit hotstreaks from the affected column are about the same as the increases in the coolant temperature rises given above. Thus, a single jet, if it were located where it does not merge with jets from other columns, could have a temperature increase as great as $280^{\circ} \mathrm{F}$.

\subsubsection{Consequences of Temperature Increases}

\subsubsection{Fuel Performance}

Fuel particles remain intact up to about $3000^{\circ} \mathrm{F}$, at which temperature their coatings begin to experience deterioration. For the worst case of a ring 2 axial zone 1 block being mislocated in ring 1 , layer 9 and assuming the maximum power column, the fuel temperatures could exceed this value for a small volume of the fuel (volume fraction $=0.00006$ ).

Based on the calculated power history for this column, the temperatures would decrease gradually from these maximum values over a 100 day period, and then decrease rapidly. Also, this burnup 


\section{FIGURE 3.4 \\ MISLOCATED FUEL BLOCK FUEL TEMPERATURES}

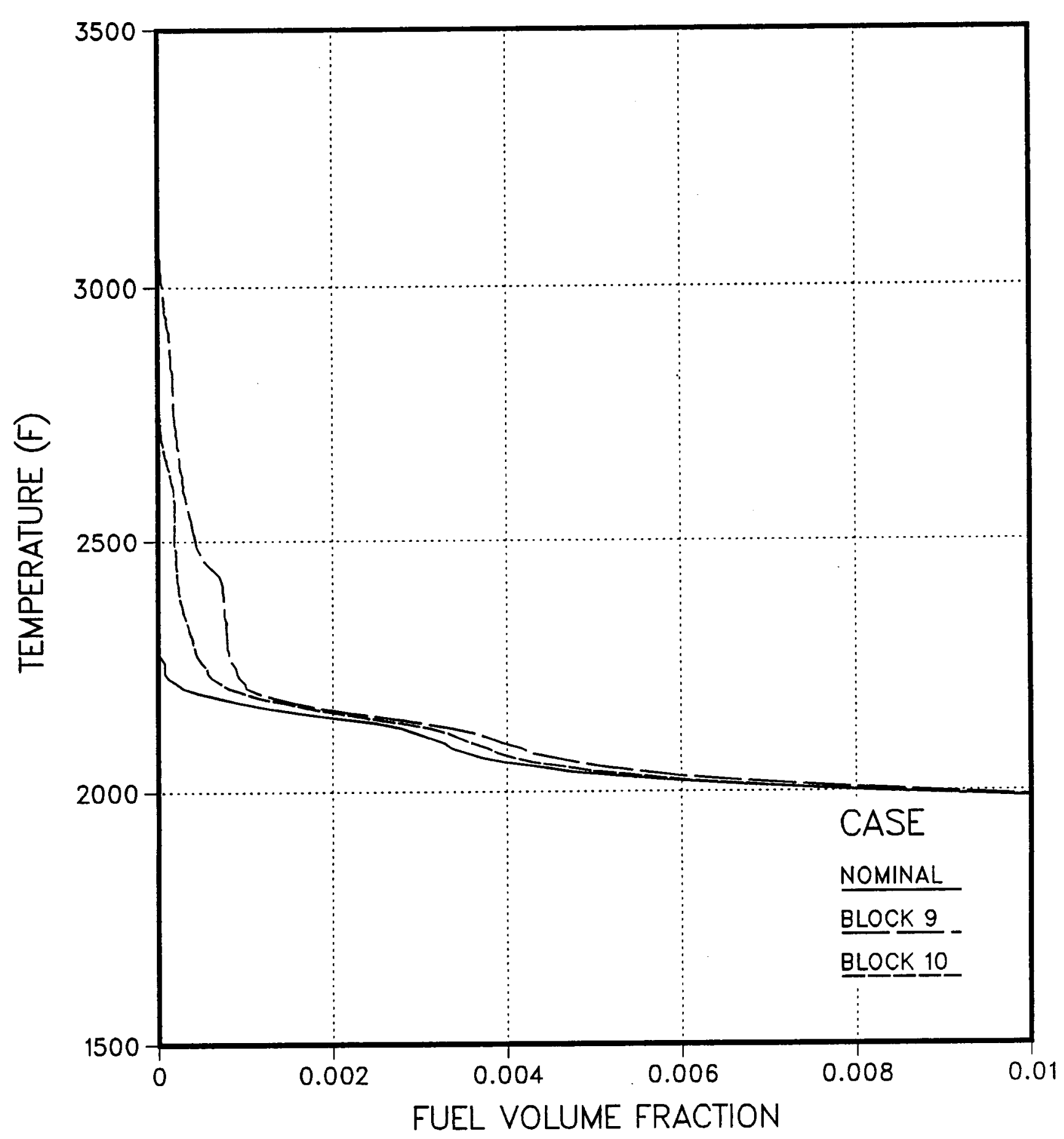




\section{FIGURE 3.5: MISLOCATED FUEL BLOCK COLUMN AVERAGE COOLANT TEMPERATURE}

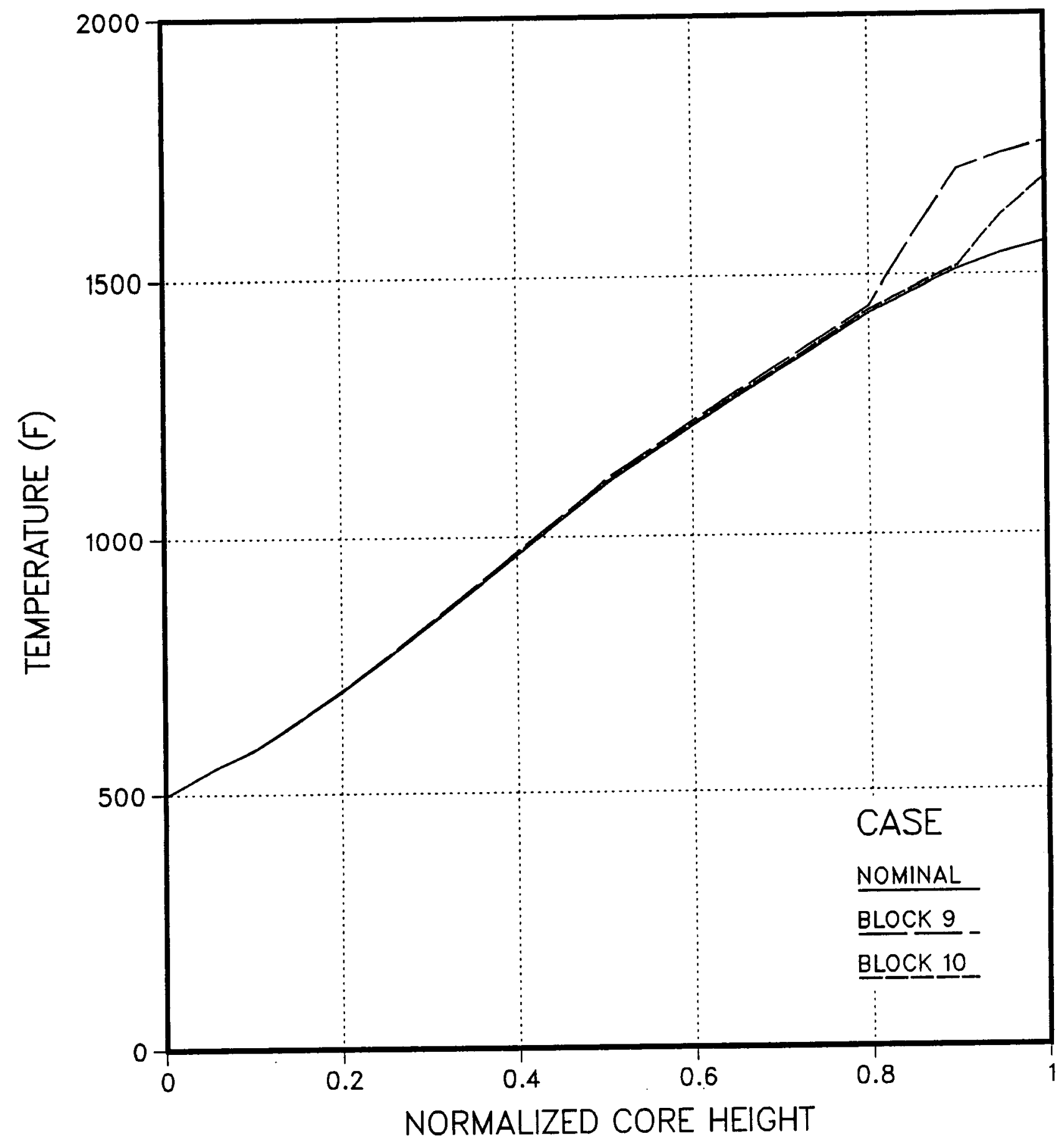




\section{FIGURE 3.6: MISLOCATED FUEL BLOCK $1 / 7$ COLUMN AVERAGE COOLANT TEMPERATURE}

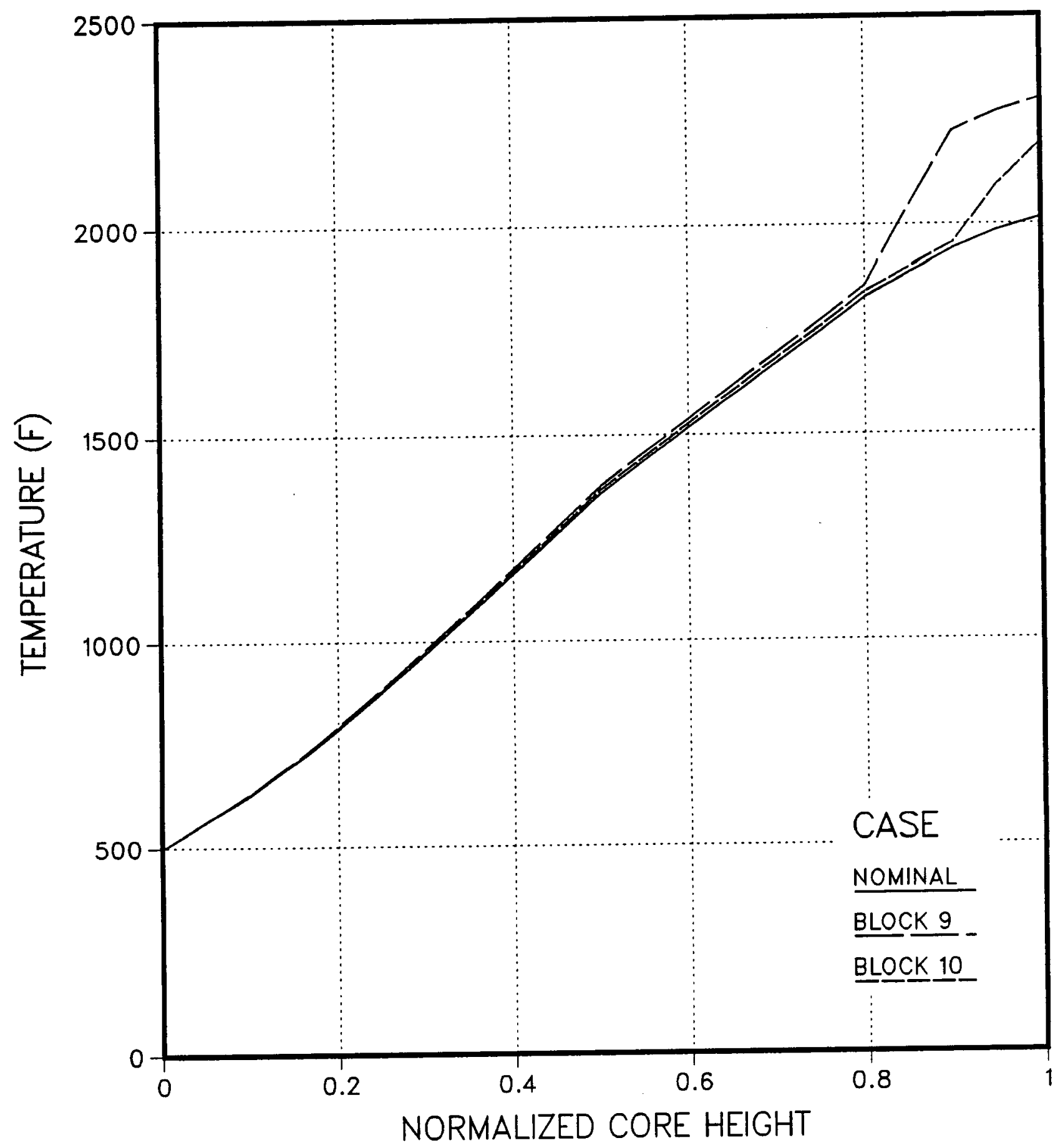




\section{FIGURE 3.7: MISLOCATED FUEL BLOCK $1 / 7$ COLUMN FUEL TEMPERATURE}

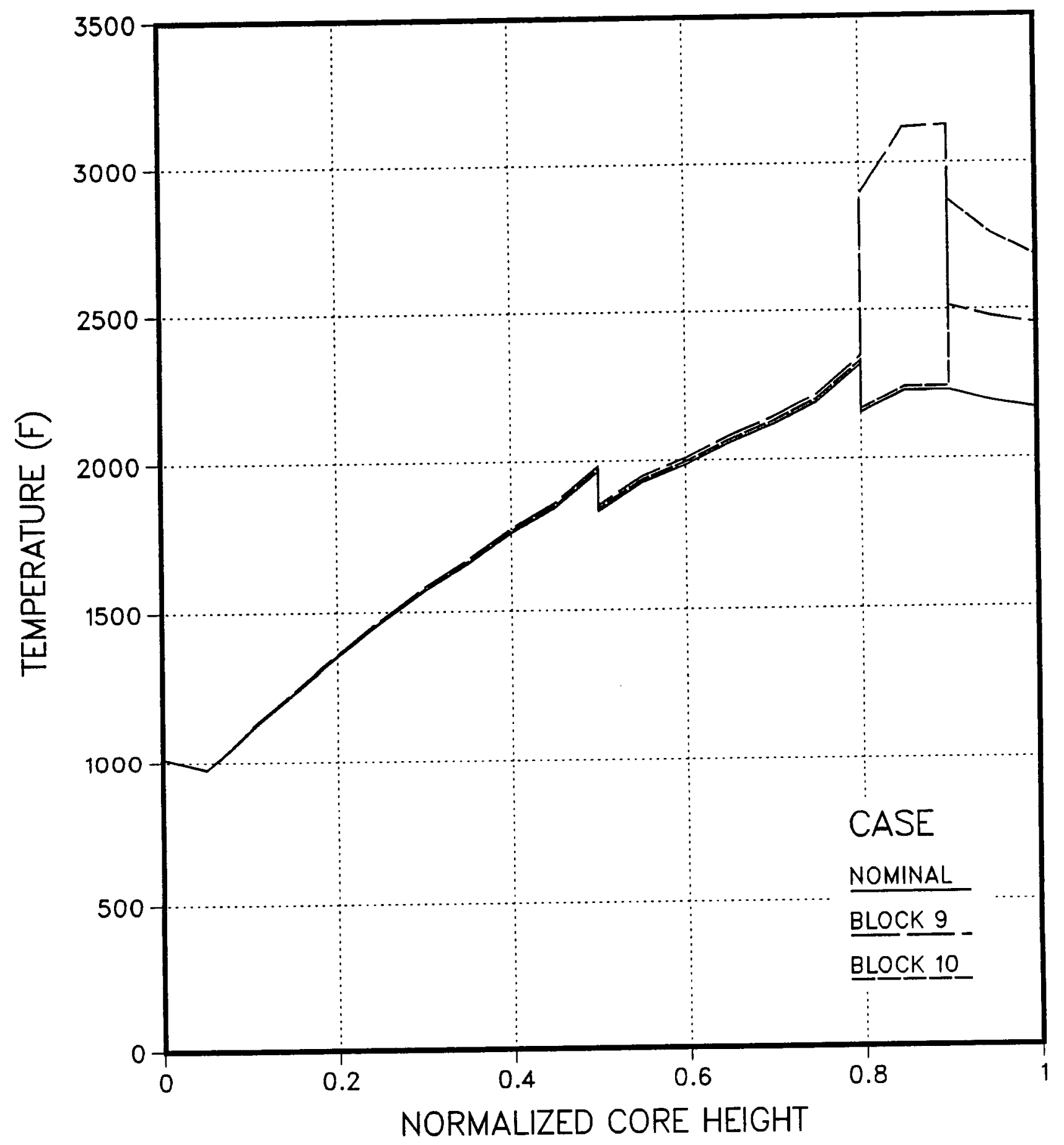


calculation was performed for the expected core fuel loadings. If a fuel element were to be mislocated as assumed in this analysis, its power would decrease more rapidly.

For the single worst case, it is expected that fuel temperatures and burnups may be high enough that fission product release would be measurably higher. It is not likely that, even for this case, the circulating activity levels would be high enough to force shutdown of the plant and replacement of the mislocated fuel block.

\subsubsection{Graphite Block Integrity}

Graphite stresses in the lower axial layer blocks are lower than at core mid-height. Further, the seismic loads are lower for these blocks. However, the much higher temperatures in the mislocated block than in the surrounding blocks will lead to large temperature gradients and attendant tensile stresses at the block periphery. Localized cracking could result.

Extensive cracking would not occur because residual stresses would reduce as a result of the limited cracking. The localized cracking would be expected to be within the graphite block design criteria.

\subsubsection{Coolant Temperature Streaks}

Increases in coolant temperature hotstreaks have been estimated for the worst case, where the $10 \mathrm{cal}$ core exit hotstreak is $280^{\circ} \mathrm{F}$. The temperature attenuation factors that were used as for the flow blockage analysis were increased by $50 \%$ for this case as an approximate way to account for the fact that the coolant temperatures are increased for all six of the core exit jets which receive flow from the affected 
column (clustering effect). The resulting hotstreak temperature increases at the hot duct and steam generator are given in the table below:

Temperature Increase $\left({ }^{\circ} \mathrm{F}\right)$

\begin{tabular}{|c|c|c|c|}
\hline Mislocated Block & Hot Duct & Steam & Generator \\
\hline Axial Layer 9 & 17 & & 3 \\
\hline Axial Layer 10 & 11 & & 2 \\
\hline
\end{tabular}

These temperature increases are small, and would persist for less than 100 days. This time is relatively small compared to the design life of 40 years. Further, the estimates are believed to be conservative because the actual location of the calculated hotstreaks is in the inner ring of the active core, whereas the attenuation factors apply to hotstreaks near the hot duct entrance.

A similar calculation for a hotstreak in the outer ring would produce smaller hotstreaks. A reasonable estimate of the reduction is the ratio of the fissile zoning factors for the inner and outer rings $[$ ratio $=0.75 / 1.04=0.72]$. If the above hotstreaks are reduced by this factor, the maximum hotstreak is $12^{\circ} \mathrm{F}$ at the hot duct and $2^{\circ} \mathrm{F}$ at the steam generator.

Although a greater risk of damage is associated with any temperature increase, the estimated values are small and not believed to be significant.

\subsubsection{Control Rods}

The temperature increases would be almost completely confined to the active core, and would have little affect on the control rod temperatures. 


\subsubsection{Detection of Fuel Block Mislocation Events}

The same measurements could be used to detect a mislocated fuel element as for flow blockage events: temperature measurements in the bottom reflector transition blocks in each fuel column.

In the discussion of flow blockage events, it was noted that a column exit coolant temperature could be higher than the expected value by as much as $174^{\circ} \mathrm{F}$ due to uncertainties in the calculated power peaking factors, flow distribution and measured temperatures. This compares to calculated column average coolant temperature increases of $190^{\circ} \mathrm{F}$ (mislocated block in axial layer 9 ) or $120^{\circ} \mathrm{F}$ (mislocated block in axial layer 10).

Thus the resulting temperature increase would be on the same order of magnitude as that due to uncertainties. As for a flow blockage event, a temperature increase due to a mislocated fuel block could alert the operator to a possible problem, but would probably not result in reactor shutdown unt 11 corrobotative evidence, most likely increased circulating activity levels in the primary coolant, were available.

\subsubsection{Probability of Occurrence of a Mislocated Fuel Element}

The chances of mislocating a fuel element were discussed in the previous section on flow blockage events. Because of the numerous checks that are performed, this is thought to be a very low probability event. No studies have been performed to quantify this small number. 


\section{REFERENCES}

1. Henderson, M., "MHTGR Core Flow Analysis for Expected (Nonuniform) Core Gaps", DOE-HTGR-88283, Issue 0, March 31, 1989.

2. Baccaglini, G. and Carosella, D., "MHTGR Primary Coolant Flow Analysis", DOE-HTGR-88224, Issue 1, May 14, 1987.

3. Lane, R. and Baxter, A., "MHTGR Core Nuclear Sensitivity Analysis", DOE-HTGR-87-085, GA Document 909508/2, November, 1987. 